\title{
Quantitative Anatomy of C7 Vertebra in Southern Chinese for Insertion of Lateral Mass Screws and Pedicle Screws
}

\author{
Michael Siu Hei Tse ${ }^{1}$, Chi Hin Chan ${ }^{2}$, Kam Kwong Wong ${ }^{1}$, Wing Cheung Wong ${ }^{1}$ \\ ${ }^{1}$ Department of Orthopaedics and Traumatology, Kwong Wah Hospital, Hong Kong \\ ${ }^{2}$ Department of Diagnostic and Interventional Radiology, Kwong Wah Hospital, Hong Kong
}

\begin{abstract}
Study Design: Retrospective study.
Purpose: To analyze the quantitative anatomy of C7 vertebra for insertion of lateral mass screws and pedicle screws in Southern Chinese patients.

Overview of Literature: C7 lateral mass is smaller when compared to other subaxial cervical levels, which limits the length of lateral mass screws that can be used. Some studies have suggested pedicle screws for better fixation. But, this option is limited by the narrow pedicle width.

Methods: We have obtained computed tomography (CT) cervical spine data in $0.625 \mathrm{~mm}$ slices from our radiology department. The patients were adults. CTs were from May to August, 2015. The lateral mass screw length was measured using Margerl's technique and pedicle width and pedicle screw trajectory were determined in three-dimensional reformated images.

Results: CT scans of cervical spines of 94 patients were obtained and 188 lateral masses and pedicles of C7 vertebrae were measured. The mean lateral mass screw length was $13.2 \mathrm{~mm}$ (standard deviation [SD] $1.6 \mathrm{~mm}$ ), mean outer pedicle width was $5.9 \mathrm{~mm}$ (SD $1.0 \mathrm{~mm}$ ) and mean pedicle screw trajectory was 29.4 degrees (SD 3.6 degrees). Most (91.0\%) of the pedicles had an outer diameter $\geq 4.5 \mathrm{~mm}$.

Conclusions: The mean lateral mass screw length was longer when compared with other similar studies, while the mean outer pedicle width was narrower. Nearly $10 \%$ of the pedicles were unable to accommodate $3.5 \mathrm{~mm}$ screws. These findings favor the use of lateral mass screws to provide a safe and stable fixation for C7 vertebrae in Southern Chinese patients, while the final choice of fixation method should only be confirmed after careful preoperative planning with CT scan.
\end{abstract}

Keywords: Cervicalvertebrae; Instrumentation; Pedicle screws

\section{Introduction}

C7 lateral mass is smaller compared to other subaxial cervical levels, which limits the length of the lateral mass screws that can be used. A screw that is too long may injure nerve roots. A screw that is too short will reduce the pull-out strength. Pedicle screws provide better fixation as a longer screw length can be accommodated while they are limited by the narrow pedicle width in the cervical spine.

In this study we analyzed the quantitative anatomy of C7 vertebra for insertion of lateral mass screws and pedi-

Received Nov 30, 2015; Revised Jan 12, 2016; Accepted Jan 22, 2016

Corresponding author: Michael Siu Hei Tse

Department of Orthopaedics and Traumatology, Kwong Wah Hospital, 25 Waterloo Road, Kowloon, Hong Kong

Tel: +23322311, Fax: +35175481, E-mail: tseshm@gmail.com 
cle screws in Southern Chinese patients and compared the data to other similar studies.

\section{Materials and Methods}

Computed tomography (CT) scans of the neck that were done for any medical condition from May to August 2015 were obtained from our radiology department. We excluded patients who were not ethnic Chinese, those with a history of cervical spine fracture or malignancy or patients with an anatomical anomaly. CT scan data acquired in $0.625 \mathrm{~mm}$ slices from 94 adult patients were included. With the cooperation of radiologist colleagues, we measured the unicortical lateral mass screw lengths, pedicle widths and pedicle screw trajectories of both sides of each C7 vertebra under three-dimensional (3D) reformatted images using a general electric Healthcare Advantage Workstation for Diagnostic Imaging. Lateral mass screw measurements were done using Margerl's technique [1,2]. The starting point was $1 \mathrm{~mm}$ medial and superior to the center of the posterior lateral mass in the $3 \mathrm{D}$ reconstructed image (Fig. 1A). We then obtained a reformatted image superiorly elevated 45 degrees based on the start point, which was tilted 45 degrees with respect to the vertical plane along the posterior border of the $\mathrm{C} 7$ lateral mass (Fig. 1B). The screw length was then measured at a trajectory of 25 degrees angulated laterally on the axial plane (Fig. 1C). Pedicle width was measured on a reformatted image. The width was the outer cortical width of the isthmus that was parallel to the pedicle axis and at the mid-point of the pedicle height (Fig. 2). Pedicle width was used instead of pedicle height as Karaikovic et al. [3] showed the cervical pedicle width was always smaller the pedicle height. Lastly, the pedicle trajectory was measured as the angle between the axis of the pedicle and the midline, which was defined as the perpendicular line to the
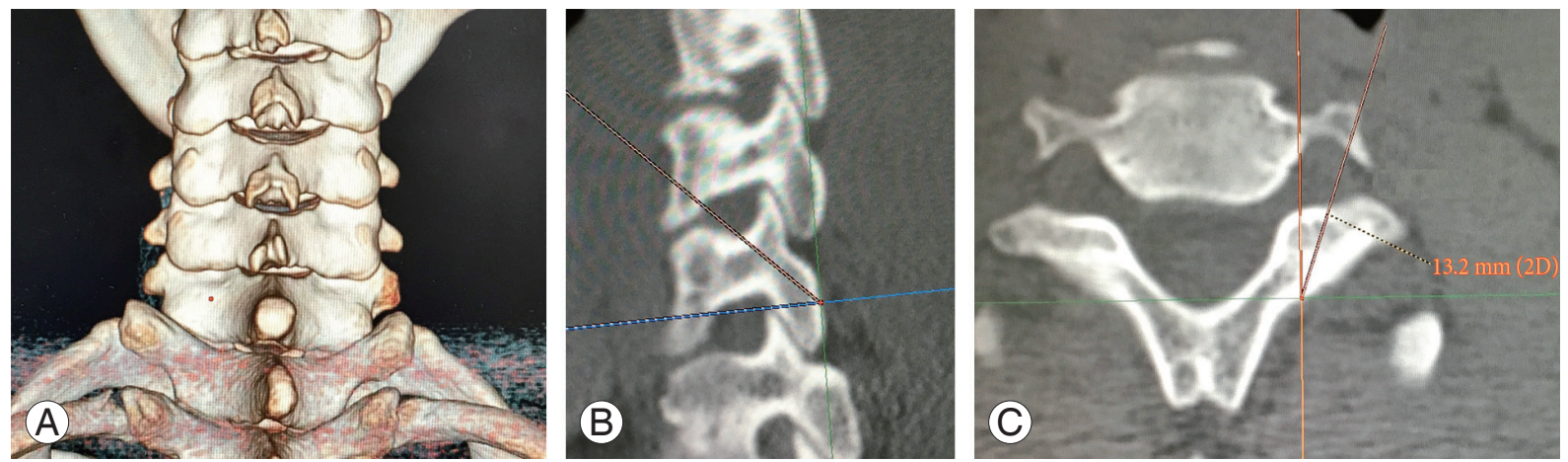

Fig. 1. (A-C) Measurement of lateral mass screw length.
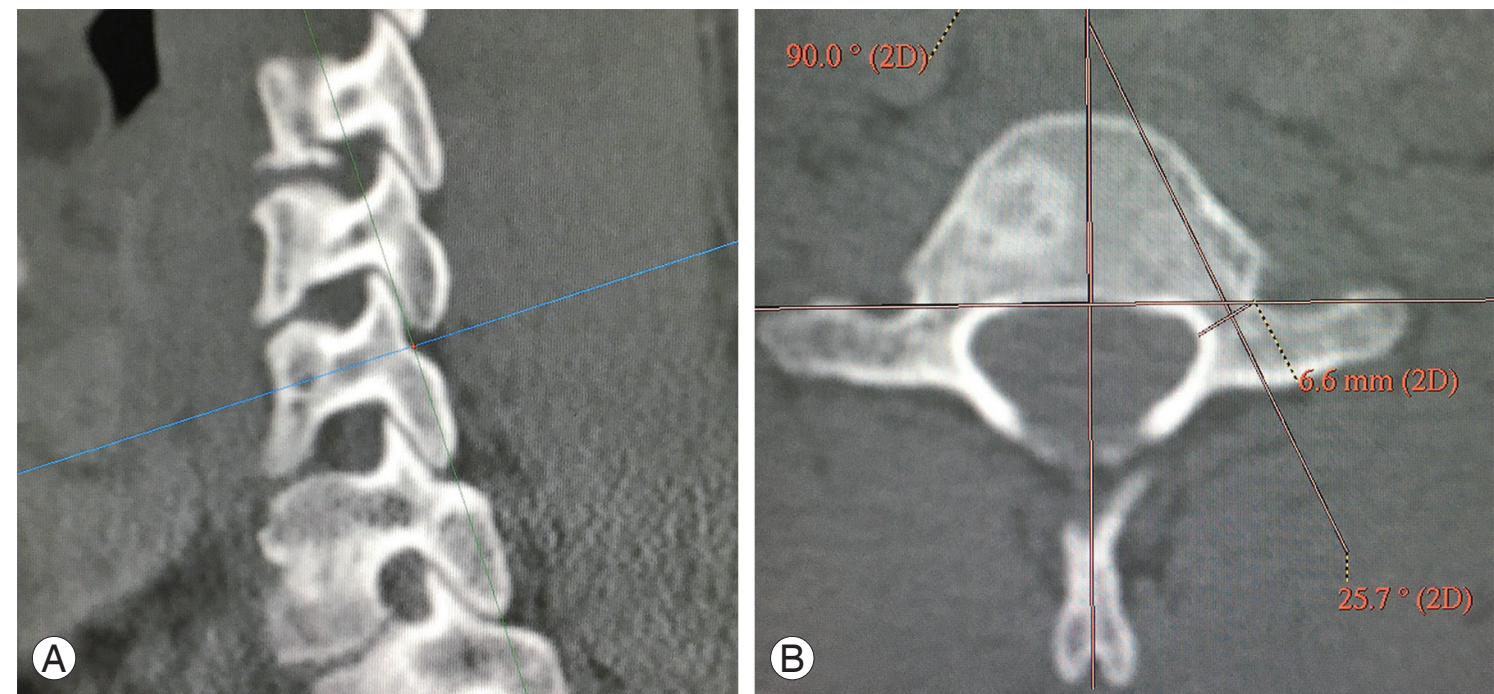

Fig. 2. (A, B) Measurement of pedicle width and trajectory. 
Table 1. Lateral mass screws length, pedicle widths, pedicle trajectories

\begin{tabular}{lccc} 
Patient & Lateral mass screw lengths $(\mathrm{mm})$ & Pedicle widths $(\mathrm{mm})$ & Pedicle trajectories $\left({ }^{\circ}\right)$ \\
Male & $13.7(1.5)$ & $6.2(1.0)$ & $29.2(3.5)$ \\
Female & $12.7(1.5)$ & $5.5(0.9)$ & $29.6(3.7)$ \\
All patients & $13.2(1.6)$ & $5.9(1.0)$ & $29.4(3.6)$ \\
\hline
\end{tabular}

Values are presented as mean \pm standard deviation.

Table 2. Comparison to other studies

\begin{tabular}{llcc} 
Study & Sex & Mean lateral mass screw length (mm) & Significance of difference \\
\hline Stemper et al. [4] & Male & 11.4 (SD 1.8) & $p<0.01$ \\
& Female & 9.6 (SD 1.5) & $p<0.01$ \\
Abdullah et al. [2] & Male & 11.6 (SD 2.8) & $p<0.01$ \\
\hline Jang et al. [5] & Female & 9.2 (SD 1.8) & $p<0.01$ \\
\hline
\end{tabular}

SD, standard deviation.

posterior vertebral body (Fig. 2).

Mean and standard deviation (SD) of lateral mass screw lengths, pedicle widths and pedicle trajectories were computed. Comparison of male to female patients used the independent sample $t$-test. The results were also compared with other studies using Welch's unpaired $t$-test. For inter-observer repeatability, a radiologist independently repeated the measurements for 10 of the patients and data were analyzed using the intraclass correlation coefficient.

\section{Results}

CT cervical spines of 94 patients (47 males, 47 females) with mean age 58.6 years (SD 17.9 years) were obtained and 188 lateral masses and pedicles of $\mathrm{C} 7$ vertebrae were measured. The mean lateral mass screw length for the patients was $13.2 \mathrm{~mm}$ (SD $1.6 \mathrm{~mm}$ ) (Table 1), with male patients having a significantly longer length than female patients $(p<0.01)$. Comparison to other similar studies revealed that the mean lateral screw mass length was significantly longer than two studies on North American patients and one study on Korean patients (Table 2). The lateral mass screw lengths were larger than $12 \mathrm{~mm}$ in $90.4 \%$ of male patients and $67.0 \%$ of the female patients. Lateral masses of all male patients and $95.7 \%$ of female patients had lengths longer than $10 \mathrm{~mm}$.

Outer cortical widths were measured as the pedicle widths. The mean value for all patients was $5.9 \mathrm{~mm}$ (SD
$1.0 \mathrm{~mm}$ ) (Table 1) with $91.0 \%$ of the pedicles larger or equal to $4.5 \mathrm{~mm}$. Male patients also had a significantly larger mean pedicle width than female patients $(p<0.01)$. In another study involving Korean patients, the reported mean outer cortical pedicle width was $6.8 \mathrm{~mm}$ (SD $1.2 \mathrm{~mm}$ ) [5], which was significantly larger than the present width $(p<0.01)$.

The mean value of pedicle trajectories was 29.4 degrees (SD 3.6 degrees), with no significant difference between males and females $(p=0.51)$.

For inter-observer repeatability, intraclass correlation coefficient for the 10 patients for whom measurements were repeated by an independent radiologist independently was 0.93 for lateral mass screw lengths and 0.82 for pedicle widths.

\section{Discussion}

C7 vertebra, being a transitional vertebra, is known for its thin lateral masses and the possible need to alter standard trajectories of lateral mass screw insertion in order to obtain adequate purchase and to avoid injuring its interior facet [6]. Presently, we focused on unicortical lateral mass screw instead of bicortical screw as the risk of injuring surrounding structures is lower. Although vertebral artery injury in $\mathrm{C} 7$ vertebra is low, as only $0.8 \%$ of individuals have their vertebral artery entering the $\mathrm{C} 7$ transverse foramen [7], there is a risk of injuring the C8 nerve root 
especially during bicortical screw insertion. In a prospective study on 21 patients with 164 lateral mass screws analyzed, there was a $1.8 \%$ risk per screw of radiculopathy with no vertebral artery or spinal cord injury noted [8]. The authors also found that the radiculopathies were a direct result of bicortical screw purchase. In another study performed on 21 cadavers it was found that when bicortical screws were used, there was a $5.8 \%$ incidence of direct arterial injury and a $17.4 \%$ incidence of nerve root injury, with all injuries caused by resident surgeon and none were caused by more senior surgeons [9]. However, when unicortical screws were used, no injuries were noted. The latter study further examined the pull-out strength of the screws and found that there was no significant difference between unicortical screws (with effective length $11 \mathrm{~mm}$ ) and bicortical screws. For the construct stiffness, longer unicortical screws were reportedly comparable to bicortical screws in lateral mass fixation through a biomechanical study on 11 human cadavers, with no significant difference in construct stiffness between longer unicortical screws and bicortical screws if patient had no laminectomy done [10]. Even in the presence of laminectomy, longer unicortical screws had no significant difference in flexion/extension and torsion, with only lateral bending stiffness having significant difference. Presently, the standard trajectory provided a reasonable unicortical screw length in C7 lateral mass for the Southern Chinese patients with a mean length of $13.2 \mathrm{~mm}$, which was significantly longer than other similar studies $[2,4,5]$. When using $12 \mathrm{~mm}$ screws, unicortical screw insertion could be achieved in $90.4 \%$ of male lateral masses and $67.0 \%$ of female lateral masses. If $10 \mathrm{~mm}$ screws were used, all male lateral masses and $95.7 \%$ of the lateral masses were able to accommodate the screw.

Subaxial cervical spine pedicle screw, first suggested by Abumi et al. [11], provides an alternative fixation method for this region. It is thought to be able to provide better stability and strength in fixation, while it carries risks of severe injuries to the spinal cord or the vertebral artery. For incidence of injury, Abumi et al. [12] described the outcomes of 180 patients who received cervical pedicle screws fixation, and reported there was one episode of vertebral artery injury and two episodes of screws causing radiculopathy, with no incidence of spinal cord injuries noted. These summed up to a $1.7 \%$ risk of neurovascular complications per patient. Additionally, $6.7 \%$ of the screws breached the wall of the pedicles. In another study involving 144 patients, there were one case of penetrating injury to the vertebral artery and one patient with transient radiculopathy, with no spinal cord injuries reported. There was also a $13 \%$ incidence of breaching the pedicle wall. Although the risks of neurovascular complications were low, the authors in both studies stressed the importance of planning by preoperative imaging, intraoperative fluoroscopy and also strict technique for pedicle screw insertion in order to minimize the chance of causing severe complications.

When comparing the fixation strength between lateral mass screws and pedicle screws, two studies showed that cervical pedicle screws had significantly higher pullout strengths when compared to lateral mass screws $[13,14]$. However, when we looked specifically at C7 vertebra and took the whole construct into account, the result was slightly different. A biomechanical study on 10 human cadavers that involved a comparison of five specimens of C4 to C6 lateral mass screws and C7 lateral mass screws with five specimens using $\mathrm{C} 7$ pedicle screws in the construct found no significant differences in flexion/extension and lateral bending stiffness between the two types of construct, both immediately after instrumentation and after cyclical loading simulating 6-week postoperative period [15]. Furthermore, as cervical pedicle screws carry a $6.7 \%-13 \%$ risk of breaching the pedicle wall $[12,16]$, we must also consider the decrease in pull-out strength when the screw protrudes from the pedicle wall. A biomechanical study that examined the effect on pullout strength in thoracic pedicle screws when the pedicle wall was breached reported that when lateral pedicle wall was breached, there was a $21 \%$ reduction in mean pull-out strength [17]. When we applied the above information to our findings, we found that the pedicle width in our Southern Chinese population was significantly narrower with a mean outer cortical width of $6.1 \mathrm{~mm}$. Assuming we were using a $3.5 \mathrm{~mm}$ pedicle screw, a minimum pedicle diameter of $4.5 \mathrm{~mm}$ was required in order to allow at least $0.5 \mathrm{~mm}$ bony wall both medially and laterally. In our study, $9.0 \%$ of the $\mathrm{C} 7$ pedicles had a cortical width less than $4.5 \mathrm{~mm}$; these would have a markedly increased risk of breaching the pedicle wall, potentially causing injuries to nearby neurovascular structure and also reducing pullout strength. This was in contrast with the description that all C7 pedicles had a diameter larger than $4.5 \mathrm{~mm}$ and could be fixed by $3.5 \mathrm{~mm}$ pedicle screws [18]. 


\section{Conclusions}

Using the standard trajectory on Southern Chinese patients, we were able to obtain a longer unicortical lateral mass screw length than previously expected. With our patients having narrower pedicles in which $9.0 \%$ of them were unable to accept $3.5 \mathrm{~mm}$ screws, in contrast to other studies where all $\mathrm{C} 7$ pedicles were wide enough for screws insertion, we prefer unicortical lateral mass screw insertion for Southern Chinese patients, as their lateral mass are more likely to be able to accommodate a longer screw for better purchase. Moreover, lateral mass screws provided an effective, safe and stable fixation over the C7 vertebra. Preoperative CT scan, however, is still the most important investigation to assess each patient's bony architecture before deciding on the final fixation method for the $\mathrm{C} 7$ vertebra.

\section{Conflict of Interest}

No potential conflict of interest relevant to this article was reported.

\section{References}

1. Jeanneret B, Magerl F, Ward EH, Ward JC. Posterior stabilization of the cervical spine with hook plates. Spine (Phila Pa 1976) 1991;16(3 Suppl):S56-63.

2. Abdullah KG, Nowacki AS, Steinmetz MP, Wang JC, Mroz TE. Factors affecting lateral mass screw placement at C-7. J Neurosurg Spine 2011;14:405-11.

3. Karaikovic EE, Daubs MD, Madsen RW, Gaines RW Jr. Morphologic characteristics of human cervical pedicles. Spine (Phila Pa 1976) 1997;22:493-500.

4. Stemper BD, Marawar SV, Yoganandan N, Shender BS, Rao RD. Quantitative anatomy of subaxial cervical lateral mass: an analysis of safe screw lengths for Roy-Camille and magerl techniques. Spine (Phila Pa 1976) 2008;33:893-7.

5. Jang WY, Kim IS, Lee HJ, Sung JH, Lee SW, Hong JT. A computed tomography-based anatomic comparison of three different types of $\mathrm{C} 7$ posterior fixation techniques: pedicle, intralaminar, and lateral mass screws. J Korean Neurosurg Soc 2011;50:166-72.

6. An HS, Gordin R, Renner K. Anatomic considerations for plate-screw fixation of the cervical spine. Spine (Phila Pa 1976) 1991;16(10 Suppl):S548-51.
7. Bruneau M, Cornelius JF, Marneffe V, Triffaux M, George B. Anatomical variations of the V2 segment of the vertebral artery. Neurosurgery 2006;59(1 Suppl 1):ONS20-4.

8. Graham AW, Swank ML, Kinard RE, Lowery GL, Dials BE. Posterior cervical arthrodesis and stabilization with a lateral mass plate. Clinical and computed tomographic evaluation of lateral mass screw placement and associated complications. Spine (Phila Pa 1976) 1996;21:323-8.

9. Park CK, Hwang JH, Ji C, et al. Comparisons of unicortical and bicortical lateral mass screws in the cervical spine: safety vs strength. J Korean Neurosurg 2001;30:1210-9.

10. Muffoletto AJ, Yang J, Vadhva M, Hadjipavlou AG. Cervical stability with lateral mass plating: unicortical versus bicortical screw purchase. Spine (Phila Pa 1976) 2003;28:778-81.

11. Abumi K, Itoh H, Taneichi H, Kaneda K. Transpedicular screw fixation for traumatic lesions of the middle and lower cervical spine: description of the techniques and preliminary report. J Spinal Disord 1994;7:19-28.

12. Abumi K, Shono Y, Ito M, Taneichi H, Kotani Y, Kaneda K. Complications of pedicle screw fixation in reconstructive surgery of the cervical spine. Spine (Phila Pa 1976) 2000;25:962-9.

13. Jones EL, Heller JG, Silcox DH, Hutton WC. Cervical pedicle screws versus lateral mass screws: anatomic feasibility and biomechanical comparison. Spine (Phila Pa 1976) 1997;22:977-82.

14. Johnston TL, Karaikovic EE, Lautenschlager EP, Marcu D. Cervical pedicle screws vs. lateral mass screws: uniplanar fatigue analysis and residual pullout strengths. Spine J 2006;6:667-72.

15. Xu R, McGirt MJ, Sutter EG, et al. Biomechanical comparison between C-7 lateral mass and pedicle screws in subaxial cervical constructs: presented at the 2009 Joint Spine Meeting. Laboratory investigation. J Neurosurg Spine 2010;13:688-94.

16. Yukawa Y, Kato F, Ito K, et al. Placement and complications of cervical pedicle screws in 144 cervical trauma patients using pedicle axis view techniques by fluoroscope. Eur Spine J 2009;18:1293-9.

17. Brasiliense LB, Theodore N, Lazaro BC, et al. Quantitative analysis of misplaced pedicle screws in the thoracic spine: how much pullout strength is lost?: 
presented at the 2009 Joint Spine Section Meeting. J Neurosurg Spine 2010;12:503-8.

18. Yusof MI, Ming LK, Abdullah MS, Yusof AH. Computerized tomographic measurement of the cervical pedicles diameter in a Malaysian population and the feasibility for transpedicular fixation. Spine (Phila Pa 1976) 2006;31:E221-4. 